\title{
A new form of familial ataxia, deafness, and mental retardation
}

\author{
W Reardon, J Wilson, N Cavanagh, $M$ Baraitser
}

\begin{abstract}
Conditions causing familial ataxia, deafness, and developmental delay are considered in the context of describing brothers with a new disorder characterised by these clinical features.

( $\mathcal{H}$ Med Genet 1993;30:694-5)
\end{abstract}

It is uncommon for hereditary ataxia of early onset to be associated with deafness and developmental delay. ${ }^{1} \mathrm{~A}$ search using these three criteria in the London Neurogenetics Database yields 20 diagnostic possibilities. ${ }^{2}$ However, most of these conditions are associated with additional pathological features involving other systems. Accordingly the differential diagnosis in the familial ataxic, deaf patient without other signs is limited to a few distinct entities.

We report brothers with an apparently undescribed form of deafness, ataxia, and mental retardation and contrast their condition with similar, but distinct, disorders.

\section{Case reports}

The family comes from Kuwait and the pedigree is shown in the figure. The proband, V.2, was born after a normal pregnancy and term delivery, weighing $2550 \mathrm{~g}$. Initial development was slightly delayed. $\mathrm{He}$ sat at 10 months, walked independently at 18 months, and had several single words by the age of $2 \frac{1}{2}$ years. $\mathrm{He}$ continued to gain skills slowly and there was no history of seizures.

On examination aged 4 years his head cir\author{
Revised version accepted \\ 8 February 1993. \\ Department of
Clinical Genetics \\ The Hospital for Sick \\ W Reardon \\ Department of \\ Hospital for Sick \\ Children, Great \\ London WC1N 3JH, \\ J Wilson \\ Department of \\ Westminster \\ Children's Hospital, \\ London, UK. \\ N Cavanagh
}

$$
\text { I }
$$

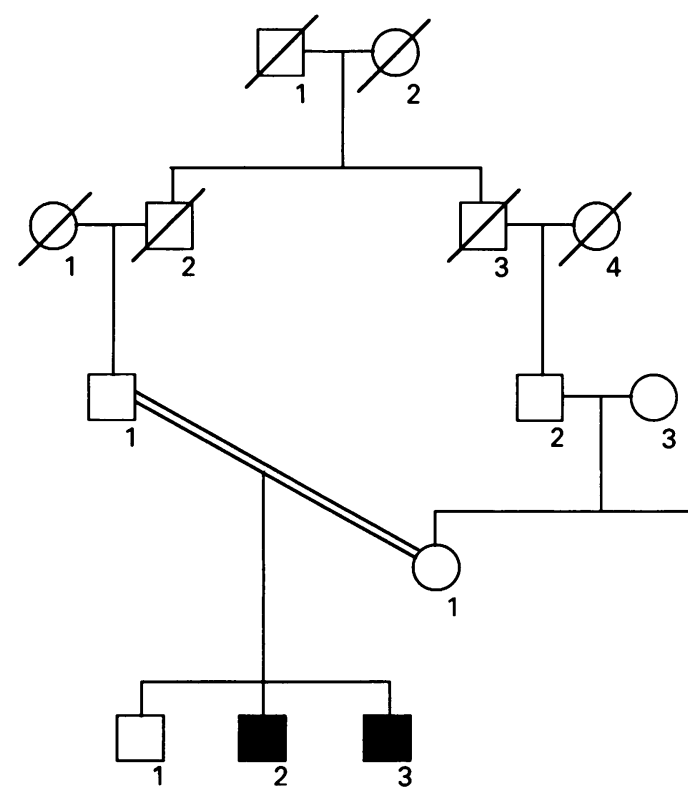

III

IV

V

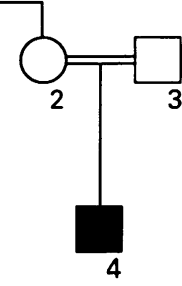

cumference was on the 50th centile, as was his height, while his weight was on the 25 th centile. Tone, power, and sensation were normal. There was no evidence of muscle wasting. Reflexes were difficult to elicit but were present and were thought to be normal. However, there were clear signs of cerebellar incoordination in his upper limbs and in his gait, which was broad based. There were no neurocutaneous stigmata. Clinical evaluation of auditory function suggested an abnormality and this has subsequently been confirmed by formal audiometry. Extensive investigation failed to show a chromosomal or metabolic basis for his developmental problems and CT scan of his brain proved to be normal. The family presented again six years later when $\mathrm{V} \cdot 3$ was referred aged 7 years.

$\mathrm{He}$ had been a term delivery, weighing $3200 \mathrm{~g}$. Pregnancy had been normal apart from mild hypertension in the latter weeks. Developmental milestones were slightly delayed, with sitting being achieved at 9 months, crawling at 9 to 10 months, and walking at 18 months. His gait was unsteady from the beginning. By the age of 3 years, he was using simple sentences, but his language development made little progress thereafter. Unlike his brother, $\mathrm{V} \cdot 3$ has had six generalised seizures, all associated with febrile episodes but none of these episodes has been prolonged beyond a few minutes. On examination, height, weight, and head circumference were all on the 50 th centile. There were no dysmorphic or neurocutaneous features. Gait was ataxic; he was unable to perform heel-toe walk or to hop. Fingernose incoordination confirmed cerebellar involvement in the upper limbs. Tone was reduced, especially in the upper limbs but power and reflexes were thought to be normal, as was muscle bulk. Assessment of hearing confirmed a severe bilateral sensorineural hearing loss with normal middle ear function, as confirmed by tympanometry. As with V.2, extensive investigations, including urinary and plasma amino acids, urinary organic acids, serum lactate, and immunoglobulins failed to show a biochemical basis for the abnormalities and CT brain scan was normal.

Both boys attended a special school, reflecting a mild degree of intellectual delay. Although not assessed, a maternal first cousin, $\mathrm{V} \cdot 4$, was said to be similarly affected.

\section{Discussion}

These brothers share similar clinical features in all respects apart from the seizures associated with fever in V.3. Essentially, theirs is a condition characterised by cerebellar ataxia, 
Comparative clinical features of this and other similar reports.

\begin{tabular}{llll}
\hline & Berman $e t a l^{3}$ & Koletzko $e t a l^{4}$ & Present report \\
\hline Age of onset of ataxia & Infancy & $8-10 \mathrm{y}$ & Infancy \\
Age of onset of deafness & $2-3 \mathrm{y}$ & $2-3 \mathrm{y}$ to $3 \mathrm{y}$ \\
Type of deafness & Sensorineural & Sensorineural & Sensorineural \\
Motor development & ?initially normal (<1 year) & Delayed from infancy & Delayed from infancy \\
Myopathic facies & + & + & - \\
Lower limb muscle wasting & + & $?$ & - \\
Extensor plantar response & + & + & - \\
Heel contractures & + & + & - \\
Evidence of peripheral neuropathy & + & + & - \\
\hline
\end{tabular}

sensorineural deafness, and global developmental delay. This triad has been observed in familial conditions by a number of previous authors. Berman et al ${ }^{1}$ reported infantile onset progressive ataxia, hearing loss initially noted at the age of 2 to 3 years, and mental retardation in three brothers out of a sibship of four boys and one girl. ${ }^{3}$ These patients were described as having a myopathic face and, in addition, had a marked degree of muscle wasting of the lower limbs which was present by the age of 6 years. By this age, hyperreflexia of the lower limbs was observed with extensor plantar responses. Subsequently heel contractures developed. EMG and sural nerve biopsy were suggestive of a mild peripheral neuropathy so whether the muscle wasting was the result of pyramidal involvement or peripheral neuropathy remains unclear. The hearing loss was progressive resulting, ultimately, in a severe sensorineural deafness. The inheritance was assumed to be autosomal recessive or $\mathrm{X}$ linked. Subsequently three affected sisters said to have the same condition were reported as confirmation of autosomal recessivity. ${ }^{4}$ As with the original report, there was a myopathic facies and the plantar responses were extensor, although the lower limb muscle wasting noted in the report of Berman et $a l^{3}$ was not commented upon. The ataxia in this second family was late in onset, being noted at 8 to 10 years, unlike the observation of Berman et $a l^{3}$ of ataxia from infancy. Thus, it is by no means certain that these two reports refer to the same condition and autosomal recessive inheritance for the condition described by Berman et $a l^{3}$ has not been proven by the second report. In contrast, the brothers we describe have normal plantar and other reflexes without evidence of pyramidal tract involvement or of peripheral neuropathy. Neither are contractures nor muscle wasting of the lower limbs features in our patients (table).

Richards and Rundle ${ }^{5}$ described three affected brothers and two affected sisters, offspring of a consanguineous union, initially of normal intelligence which then gradually deteriorated from the age of 5 or 6 years, with obvious dementia in the second decade of life. A similarly affected sib pair may previously have been described by Koennecke. ${ }^{67}$ Ataxia developed early and progressive deafness was initially noted at about 2 years of age but deteriorated to leave a severe sensorineural loss. Tendon reflexes became reduced with age and talipes and claw hand were features of the second decade. Secondary sexual characteristics did not develop and the external genitalia were small. Although the subjects of this report have yet to reach the age of developing secondary sexual features, their clinical course differs from that of the Richards and Rundle syndrome $^{5}$ in that there has been no evidence of regression. In addition, there is no evidence of pyramidal tract signs in the lower limbs.

Patients with Vialetto-Van Laere syndrome also have deafness, ataxia, and mental retardation. However, in this disorder, which may comprise a number of separate conditions with differing modes of inheritance, bulbar palsy is a key feature. Neither of our patients showed any evidence of bulbar weakness. Similarly, the $\mathrm{X}$ linked condition described by Schmidley et $a l^{8}$ can be ruled out by the absence of optic atrophy ${ }^{8}$ in the current report, and the autosomal recessive disorder described by Saul and Stevenson ${ }^{9}$ in sibs with deafness, ataxia, and retardation was also characterised by an extreme degree of emotional lability, ${ }^{9}$ which we have not observed. Mild incoordination was seen in two of the three cases, but the author states that this "was not suggestive of ataxia".

In summary, we report brothers with ataxia, sensorineural deafness, and global developmental delay, who appear to represent a new genetic entity. Autosomal recessive inheritance seems likely in view of the parental consanguinity, but the presence, by family report, of an identically affected maternal male first cousin leaves $\mathrm{X}$ linked inheritance still a possibility.

1 Harding AE, et al. Hereditary ataxias and related disorders. Edinburgh: Churchill Livingstone, 1984.

2 Winter RM, Baraitser M. The London neurogenetics database. Oxford: Oxford Medical Press, 1993.

3 Berman W, Haslam RHA, Konigsmark BW, Capute AJ, Midgeon CJ. A new familial syndrome with ataxia, hearing loss and mental retardation. Arch Neurol 1973;29:258-61. 4 Koletzko S, Koletzko B, Lamprecht A, Lenard HG. Ataxiadeafness-retardation syndrome in three sisters. Neuropediatrics 1987;18:18-21.

5 Richards BW, Rundle AT. A familial hormonal disorder associated with mental deficiency, deaf mutism and ataxia. f Ment Defic Res 1959;3:33-55.

6 Koennecke W. Friedreichsche Ataxie und Taubstummheit. $Z$ Gesamte Neurol Pathol 1920;53:161-5.

7 Konigsmark BW, Gorlin RJ. Genetic and metabolic deafness. Philadelphia: Saunders, 1976.

8 Schmidley JW, Levinsohn MW, Manetto V. Infantile Xlinked ataxia and deafness: a new clinicopathological entity? Neurology 1987;37:1344-7.

9 Saul RA, Stevenson RE. Deafness, mental retardation and behavioural disturbance in three siblings. Proc Greenwood Genet Centre 1988;7:7-8. 